\title{
THE FUNCTIONAL AND AESTHETIC VALUES FOR THE SIGN THROUGH ANCIENT CIVILIZATIONS AS AN ENTRANCE TO ENRICH THE VISUAL AND CULTURAL FORMULAS OF THE CONTEMPORARY SERVICE SIGN
}

Amani Ramadan Mustafa MANSOUR *

Graphic Department, College of Fine Arts, Minia University, Egypt

\begin{abstract}
Since the dawn of time, symbols have expressed the human arts, so the visual language was through Functional and aesthetic values of ancient civilizations, and visual culture comes as an integrated system of signs, symbols, visual cultural formulas, shapes, relationships and contents bearing the experiences and balance of civilized The contemporary service mark with its features and carries with it the thought and civilization of the nation. The researcher has seen that the signs across ancient civilizations and the functional and aesthetic values they represent can form an important axis from which the designer can start to enrich the visual cultural formulas of the contemporary service mark peoples and is characterized by Introduction.

Keywords

Functional, Aesthetic Values, The Sign, Ancient Civilizations, An Entrance, The Visual And Cultural Formulas, The Contemporary Service Sign.
\end{abstract}

\section{Introduction:}

The symbol and the human, animal, or botanical elements it contains are considered as a visual means of communication and birds, and as soon as the symbol is designed to be used as an ancient identification mark the age of mankind, but it has not crystallized as it can determine its meaning through the circumstances in which it is used, theoretical pillars except With the beginnings of the twentieth century, this does not mean that culture is the specific framework for understanding the meanings and uses, meaning that it was far from the reflections and efforts of thinkers in the symbol as signs, and every human society has its own culture in the cognitive domain, the Greeks began the organized meditation of the sign in its ores, which differ in their entirety from the culture of any Another society, the first century AD, when they were interested in the study of analysis, which is also a language or code Its people know it and the signs are trying to solve it, and in the second century AD the distinction between, but it is a mystery that carries with it the culture of this community General that denotes more than one thing, signs and plastic art is a visual message that carries an idea for a private sign that indicates a specific thing.

It has a communicative cognitive connotation that the recipient receives in the form of either. The contemporary service sign is linked to the environment of thought, a sign (iconic) or a 
THE FUNCTIONAL AND AESTHETIC VALUES FOR THE SIGN THROUGH ANCIENT CIVILIZATIONS AS AN ENTRANCE TO ENRICH THE VISUAL AND CULTURAL FORMULAS OF THE CONTEMPORARY SERVICE SIGN

symbolic sign. The idea or significance is the contemporary through its focus on visual formulas in art. The visual culture is that which transforms shapes and formulas by placing meanings and their connotations in a cultural context that includes the visual to the focus of semantics production. The contemporary artist who has historical, political and economic experiences, etc. As the entirety of art experiences always stands between understanding the heritage and contemplating the intellectual connotations evoked by the contemporary service mark from artistic traditions, because nature is what imposes itself on the artist during its iconic and formative dimension is not the product of a material substance in different eras as a result of its specific trends that are perceived by a function on its own Rather, it is in human practice and part, no matter how many language, of plastic expression; This is why heritage has become one of them, with indicative intellectual and moral dimensions that go beyond the formative dimensions expressing the history of society, and it has also become a basic pillar of the physical and functional form. One of the pillars of plastic art culture, where we find the characteristics of this. Culture in its entirety appears to be a system of signs linked to heritage that appears across different artistic ages and its functional values with the culture of a people trying to express its interior with these signs and aesthetics, One of the most important features of contemporary in this century is the nature of the existence of the aesthetic values of the sign across ancient civilizations, the relationship between the artist and the visible reality, not everything new in art, and its connection with the quality of that function it performs.

\section{The goal of research}

Because it does not necessarily meet an intellectual or material need, the goal is always to upgrade the age; The more it is related, the research aims to: the service mark of the era, the more strength and aesthetic value it increases

A- Identifying the functional and aesthetic values of the mark through and functional, so the service sign should be a reflection of the foundations of the ancient civilizations of their age.

B- Identifying the effect of the functional and aesthetic values of the mark through the formulas of visual culture of the service mark as one of the ancient civilizations as an entry point for enriching the visual cultural formulas of the important issues in our contemporary world which need further research and study for the contemporary service mark because of its effective role in c- Creating experimental approaches To enrich cultural formulas visual aesthetic response and form the convictions of the recipientService signs and their functional values occupy new, through benefiting from thought, a great deal of interest in institutions or aesthetics across ancient civilizations. Companies alike, and this interest is increasing in the time of $\mathrm{d}$. Reaching 
a set of proposals and results that globalization As it is an important guide for the recipient who can, by helping to enrich the visual cultural formulas of the service mark, identify the source of products and services and their distinction, and thus facilitate the marketing and service process on him. Therefore, among the importance of research is The most important strategic priority for any marketing or service activity for research is theoretical importance and practical practical value: for any institution is its keenness and constant search for the establishment of a mark

A- Scientific theoretical significance: it is distinguished from its competitors and is closer to the recipient in order to enrich Arab studies by identifying the values, preserving them and achieving satisfaction with them, and the functional and aesthetic access to the mark has been achieved through ancient civilizations. The degree of total loyalty to its products and services . This study could be an introduction to more research studies, and for this it is necessary to pay attention to artists and graphic designers to advance in the field of functional and aesthetic values of the mark by establishing a system of abstract signs and symbols and to enrich them in ancient civilizations.

The form of visual cultural formulas created through the benefit of This research provides results and ideas for an entrance to enrich the cultural formulas functional and aesthetic values across ancient civilizations, to be the visual language of the contemporary service mark by recognizing the expression and the connection between the artist and the recipient, and for the art language to transform the functional and aesthetic values of the mark across ancient civilizations within a short period of time dependent on direct transmission For the items B Scientific application importance: natural to identifying symbolic elements and iconic signs to form - This research helps decision-makers in institutions, elements and vocabulary of discourse and communication in artistic work with companies to describe methods and methods that the recipient can. Help to enrich the visual cultural formulas of the service mark. There is no doubt that cognitive development goes hand in hand with contemporary. Different civilizational, technical, cultural and social development - due to the presence of many different brands, products of peoples, As the cognitive means and methods of displaying services have evolved, companies have to focus on values and providing information, so the need has become dire greatly, functional and aesthetic as an entry point to enrich the cultural formulas of visual interpretation, interpretation of the mark, its transformations and its psychological effects, the contemporary service mark because of its positive effects on social and in light of the cultural transformation. And technical and long term multiplicity. Means of knowledge and the development of methods of semantic interpretation of a concept. 


\section{The concept of hypothesis}

1- Thought produces signs and symbols across civilizations: and the components of the sign The ancient approaches are useful approaches in extracting and enriching cultural formulas that can identify the problem in the need to enrich visual formulas that can be used in the design of the visual cultural mark of the contemporary service mark to monitor and document contemporary service.

7- A positive relationship between the visual cultural formulations developed from the functional and aesthetic values of signs and symbols across ancient civilizations and the mark between undergraduate art education students.

\section{Research Methodology:}

The research follows a descriptive and analytical approach. Attitudes Toward Sign Attitude Loyalty to the Mark The Value of the Service Mark Sign Loyalty Sign Equity Habit Descriptions Things that are a function and in other words, the theoretical framework: the service sign: counting the service mark is a visual speech.

Affecting the attitudes and habits towards the mark on an individual or group of recipients (as a society), and it is the message of the value of the visual service mark that is transmitted with its components to the imagination of the recipient, which reveals the functional and aesthetic values of the service mark: for reactions to the design direction (visual discourse) the functional values are related to an extent What is the process of innovation and that as the designer's rhetorical tool towards the recipient.

\section{References}

1- Jamal, Shaima (2009) Contemporary plastic formulas with functional and expressive connotations, i, Amman: Waves for publishing a wooden work inspired by the singular eye through and distribution. Egyptian Civilizations, an unpublished master's thesis, second: periodicals, magazines and newspapers: Faculty of Education, Minia University.

2-Abdo, Abeer Hassan (2009) The Visual Composition

3- Khattab, Muhammad Fawzi (2009), the strands formations for the brands of Egyptian tourism companies and Islamic braids as entrances to enrich roofs and their role in achieving identity, Science and Arts Magazine,

4- Woodwork, unpublished MA thesis, Helwan University, April, p. - At the disposal of the Faculty of Art Education, Helwan University

5-Ghazwan, Mu'tazanad (2012) The Conflict between Culture 
6- Ateeq, Ashi (2012). For a trademark and its impact on and modernization in the visual and graphic discourse, Journal of the Algerian Consumer Behavior, a $\mathrm{PhD}$ thesis other than the Iraqi Scientific Academy,

7. Publication, Faculty of Economic, Business and Sciences 4-Ghazwan, Moataz Enad (2012) Intellectual Implications for Management, Abi Bakr University, Algeria. The Symbolism of Islamic Art in Contemporary Design, Magazine

8- Allam, Mahmoud Mustafa (2012) The Symbolic Vocabulary of Arts, University of Baghdad, (101), p.

9- Naguib, Muhammad and Abd al-Fattah, Sami (2009) Contemporary Considerations (plastic vision), a non-semiotic $\mathrm{PhD}$ in product design, a published science journal, Faculty of Fine Arts, South Valley University and the Arts,

10-Mahmoud, Muhammad Husayn (2000) Plastic data Third: Conferences: Some recent artistic trends and their use in -

11- Al-Ajmawy, Ihab Muhammad Sabry (2010) Mechanisms for Building Enrichment of Woodwork among Artistic Education Students The distinct identification identity of Egyptian institutions in the undergraduate level, an unpublished master's thesis, in the shadow of cultural and media globalization, Mansoura University, College of Education, Minya University. https://medium.com/@inkbotdesign/hist ory-of-the-pepsi-logo-designa0db 24715722. 19// 18Chaudhuri, A. (1995). Brand equity or double jeopardy, journal of product and brand Management, Vol.4,No,pp26-32 19- Fishen. Kathren (2005). Redesigning Identity.USA: Rockport Pulisher,p9-11 20- Jonathan, B.(2005).VisualCulture. Retriev Frrom: https:// WWW.enceclppedia.com/doc/102

\section{2- Amal Farag SOLIMAN, THE AESTHETIC AND COMMUNICATIVE VALUES OF} ILLUSTRATIONS USED IN INFOGRAPHIC, International Journal of Multidisciplinary Studies in Art and Technology, Vol. 2, No. 2, 2019, pp. 14-23.

13- Sherif Massad Muhammad AREF, THE AESTHETIC AND FUNCTIONAL RELATIONSHIP OF THE MINERAL GATHERING IN ISLAMIC ART, International Journal of Multidisciplinary Studies in Art and Technology, Vol. 2, No. 2, 2019, pp. 24-28.

Received: February 7, 2020

Accepted: April 11, 2020 